\title{
MECANISMOS DE REFERENCIALIZAÇÃO E PRODUÇÃO DISCURSIVA
}

Edna Maria F. S. Nascimento*

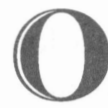

termo referencialização implica a produção de uma referência, ou seja, aquilo a que uma coisa se refere, conta ou relata. Para se referir, contar, o homem utiliza signos que, pelo fato de serem signos, são sinais, marcam alguma coisa, são um valer por.

A concepção tradicional de signo tende a equipará-lo a significante, entendendo que o referente é o próprio objeto, elemento que se situa fora da língua. Nessa acepção, o signo vale pelo objeto.

Saussure, no famoso Curso de lingüistica geral, publicado em 1916, postula o signo como uma unidade dupla, denominada por ele, significado e significante, opondo essa unidade lingüística à concepção tradicional, que a concebia como unidade de uma única face: o significante que tinha como referente um elemento do mundo natural. Diz Saussure em relação a essa concepção: primeiro o objeto, depois o signo, o que negaremos sempre (1970: 97). Posição que cai por terra, se observarmos que há substantivos que não têm referente no mundo natural, como sereia, minotauro ou amor, ódio. Ao conceber o signo como unidade de duas faces, Saussure deixa de lado a falácia do objeto. O significado, a que corresponde um significante, é um componente psíquico, mental e, portanto, lingüístico, nada tendo a ver com a realidade que é extralingüística. A lingua é entendida, por

* Universidade Estadual Paulista - UNESP/Araraquara. 
NASCIMENTO, Edna Maria F. S. Mecanismos de referenciação e produção discursiva.

Saussure, como um sistema de signos. Com a inclusão do significado na concepção do signo lingüístico, insere-se o conceito dentro do sistema lingüístico, conferindo à Semântica um lugar no interior da Lingüistica. Nessa concepção de língua, o signo é fruto de um contrato fiduciário e a língua equivale a um dicionário comum a todos. O conceito a que se refere uma unidade lingüistica é congelado em estado de língua, cobrindo a função referencial ou denotativa da linguagem. A lingua é, por conseguinte, um sistema, um código comum que o falante não pode alterar.

Como todos sabemos, o objetivo de Saussure não foi construir uma teoria semântica, mas uma teoria mais geral que desse conta da língua como um todo. Construindo as bases de uma Lingüística que pretende estudar a lingua por si própria ou como um fim em si (1970: 25), que mais tarde será denominada estrutural, os ensinamentos do mestre genebrino permitiram que seus sucessores desenvolvessem estudos que, em geral, diziam respeito às formas da língua: a fonologia e a morfologia.

Desde que o sentido também se tornou pólo de atração da Lingüística, o problema do referente passa a ser colocado sob novas bases científicas que buscam examinar a sua construção em uma dimensão maior do que a frase. A Lingüística do texto/ discurso já deixa vislumbrar, grosso modo, a nosso ver, duas vertentes que buscam a contrução daquilo a que o texto se refere, ou seja, a sua referência: a gramático-textual e a enunciativa.

Para a corrente gramático-textual que postula, com Van Dijk, uma competência textual, buscando descrever o significado como uma relação de coerência entre microestruturas lingüísticas e macroestruturas conceptuais, a referência construída encontra respaldo nos conhecimentos de mundo dos falantes. Esse conhecimento de mundo a que o texto se refere é adquirido à medida que vivemos. Mas ele não é arquivado na memória de maneira caótica, é armazenando em blocos que se denominam mo- 
delos cognitivos. As estruturas cognitivas reconhecidas são escalonadas em modelos que se constituem em conhecimentos armazenados na memória sem que haja qualquer ordenação entre eles, os frames, como, por exemplo, carnaval que ativa confete, serpentina, etc, até os scripts, que são conjuntos de conhecimentos sobre modos de agir altamente estereotipados em dada cultura, inclusive em termos de linguagem, ou seja, os rituais religiosos, as fórmulas de cortesia. Com esses modelos ideais de arquivar o conhecimento, ou situações ideais, a Lingüística Textual busca descrever, em nivel de estrutura profunda, a organização de sentido que subjaz ao texto. A referência é homologada, portanto, no contrato entre elementos microestruturais e macroestruturais, ou seja, em uma Semântica Global. Só o significado do signo não basta para a construção da referência textual. Cabe ao falante ideal o papel de interpretar os fatores de coesão da microestrutura lingüística, os exofóricos, como os dêiticos, por exemplo, e endofóricos, anáforas e catáforas gramaticais para citar um par correlato, que ativarão os conhecimentos de mundo introjetados, construindo uma referência a que se relaciona o texto. A coerência estabelecida pelo falante ideal é responsável pela construção de uma referência que, parece-nos, já se encontra a priori em um contexto situacional pré-construído.

A partir de uma concepção pragmática de linguagem como comunicação, a referência para a Lingüística Textual é fundada em um acordo estabelecido em uma situação de interação que ativa conhecimentos de mundo partilhado. Privilegiando a "armadura” do texto, a sua descrição na linearidade de superficie, ou microestruturas, embora reconhecendo um nível macroestrutural de descrição dos significados como esquemas cognitivos, a preocupação é com o significado denotado, elaborado por um sujeito ideal.

Se a gramática do texto procura descrever por meio de um falante ideal, de uma competência textual, a referência de um 
NASCIMENTO, Edna Maria F. S. Mecanismos de referenciação e produção discursiva.

texto, a vertente enunciativa busca determinar no texto as marcas da produção dessa referência, fundamentada nas concepções de Benveniste.

Depois da fase de expansão estruturalista, onde a lingua é vista como um sistema atemporal, a Lingüistica se vê de frente com os problemas da enunciação, com o processo que a temporaliza em um tempo e um espaço. A vertente enunciativa, de inspiração benvenistiana, que privilegia o ato de enunciar, da apropriação da língua para torná-la discurso, desdobra-se em duas posturas que, por sua vez, encaram a produção da referência sob perspectivas diferentes: a AD Francesa e a Semiótica da Escola de Paris.

Se fora da unidade texto, o signo refere-se a um conteúdo determinado, na língua em funcionamento esse conteúdo está sujeito às coerções de uma escolha. A referência textual está estreitamente ligada à enunciação. O signo isolado tem apenas uma referência cristalizada, é no ato de uma enunciação que ele passa a ter uma referência particular.

Tentando elaborar uma semântica da enunciação, ou seja, a transformação de conteúdos comuns em conteúdos de um discurso, o conceito de enunciação é explicitado por Benveniste no artigo "O aparelho formal da enunciação" (1989: 82): A enunciação é este colocar em funcionamento a lingua por um ato individual de utilização.

Para a Análise do Discurso Francesa, fundamentada na teoria enunciativa de Benveniste, a referência discursiva é construída. Tomando como base a AAD de Pêcheux que considera a língua como instrumento de poder, uma prática social, que se manifesta no discurso de uma instituição, expressão substituída - por influência de Althusser - por formação discursiva, a $\mathrm{AD}$ vê o sentido como um subcódigo, sob o influxo de Jakobson (1993: 73). 
A referência é fruto de um interdiscurso que circula nas diferentes instituições de que se compõe a sociedade humana, como comenta Pêcheux em AAD-69 (1993: 68).

O semema para a $\mathrm{AD}$ refere-se à construção de um autodicionário que deve usar o sujeito por fazer parte daquele grupo, ou seja, o sujeito é assujeitado pela linguagem daquele grupo que representa uma determinada formação discursiva. Para essa vertente, a enunciação e o sentido são frutos de uma prática social e a referência é homologada nos diferentes discursos que perpassam a sociedade.

A enunciação e a referência, nessa concepção, dependem das condições institucionais, ou seja, dos lugares marcados que devem ocupar o sujeito na hora de produzir o seu discurso. É enquanto sujeito que qualquer pessoa é "interpelada" a ocupar um lugar determinado em um sistema de produção que já possui referências pré-determinadas. Em outras palavras, todo sujeito humano, isto é, social, constrói referências a partir de uma prática social.

A Semiótica da Escola de Paris, por sua vez, fundamenta-se, basicamente, em três teóricos da linguagem: Saussure, Hjelmslev e Benveniste. Se lembrarmos que a Semiótica não estuda a realidade cultural, mas busca construir um conhecimento da realidade fenomênica, tal como se espelha nos diferentes sistemas que a re-criam - uma modelização do mundo, um simulacro da realidade, instituída pela sociedade que criou esses sistemas - vemos que ela tem como partida a concepção de signo do mestre genebrino que, ao postular o signo como uma unidade de duas faces, elimina a falácia do objeto. Ampliando a noção de signo de Saussure, Hjelmslev descreve-o como composto de figuras, ou seja, uma entidade não fixa que produz signos. Para Hjelmslev, o signo é então uma unidade de configuração e a língua, um sistema de figuras, nāo-signos, que, ao se combinarem, produzem signos. Na concepção hjelmsleviana, o significado se impõe, não como uma 
NASCIMENTO, Edna Maria F. S. Mecanismos de referenciação e produção discursiva.

unidade fechada, pré-construída, estática e a língua não é considerada como um sistema de signos, como podemos supor na concepção saussuriana. É a partir de figuras e não de signos que podemos, segundo Hjelmslev, dar conta da estrutura interna da linguagem, ou seja, da álgebra da linguagem. Para o lingüista dinamarquês, diferentemente do lingüista genebrino que concebia a significação como uma relação fixa, um produto, um acordo convencional, entre significante e significado, e a lingua como um sistema de signos, a língua é um sistema de figuras que produz signos ao estabelecer uma relação de solidariedade entre plano de expressão e plano de conteúdo. O signo é portanto resultado de uma função semiótica ou semiose, propriedade de criar signo, que se efetua no momento do ato da linguagem em processo, nada tendo a ver com a realidade extralingüística (1975: 62). Sendo o signo composto de figuras, ele não é apenas representação, ou seja, só denotado, mas, se para um plano de expressão podemos ter dois conteúdos, temos conotação, ou, ao contrário, se dois planos de expressão equivalem ao mesmo conteúdo, metassemiótica. O signo pode então ser descrito em funcionamento, nas três dimensões da linguagem: em denotada ou representacional, ou seja, em relação ao conteúdo previsto na lingua, em conotada ou retórica ou poética, isto é, em relação a um subcódigo autônomo, e em relação à própria linguagem, ou tradução para um subcódigo social, numa dimensão metassemiótica ou metalingüîstica.

As três semióticas ampliam a visão monolítica do significado do signo de Saussure. O conteúdo não é fixo, nem se refere $a$ priori a uma objeto como na sua acepção tradicional. E se lembrarmos que para Hjelmslev signo equivale a texto, e texto é a expressão de um conteúdo conformado sob qualquer linguagem, essas três semióticas dizem respeito ao funcionamento sui generis de qualquer linguagem, verbal, visual, etc.

A tridimensionalidade referencial proposta pelo signo de Hjelmslev, alêm de ratificar a posição do Saussure de banir o 
objeto das preocupações da linguagem, explica a significação não como um acordo pré-estabelecido, mas um acordo a se fazer pelas junções de figuras dos planos de que se compõe qualquer linguagem. A imanência de qualquer sistema é então postulada, por Hjelmslev, com mais clareza. Esse fato leva Amacker (1975) a considerar a formalização de Hjelmslev forte, ou mais profunda, e a de Saussure em um grau mais fraco, ou mais superficial. A tridimensionalidade sígnica representa, portanto, um alargamento do campo da Lingüistica, preocupada somente com a função denotativa ou referencial da lingua e reverte também em proveito de toda a Semiologia moderna.

Ao postular a autonomia, o caráter imanente da lingua e, pela mesma razão, a impossibilidade de recorrermos a referente externo (objeto do mundo dito real), a teoria saussureana, reforçada por Hjelmslev, possibilitou a semiótica a inscrever entre suas preocupações, não o problema da verdade, mas o do dizer verdadeiro, da veridicção e das condiçōes de produção de verdade.

Essa mudança de recorte epistemológico significa reconhecer que qualquer discurso constrói o seu próprio referente interno. O objeto de interesse deixa de ser, portanto, o referente dado a priori e passa a ser os mecanismos utilizados pelo sujeito da enunicação para produzir efeitos de realidade. Segundo Greimas, no Dicionário de Semiótica, o exame do procedimento da criação de ilusão referencial, denominado por ele referencialização, visa a descrever as referências estabelecidas entre o enunciado e a instância de enunciação, referencialização externa, e a rede das referências no interior do enunciado, referencialização interna. A primeira diz respeito diretamente aos dêiticos, que não têm sentido se não em relação às circustâncias de enunciação, e são preenchidos por antropônimos, cronônimos e topônimos, a segunda refere-se à anaforização e à cataforização, mecanismos pelos quais o discurso, apoiando-se em si mesmo, retoma uni- 
NASCIMENTO, Edna Maria F. S. Mecanismos de referenciação e produção discursiva.

dades lingüísticas já produzidas anteriormente com a finalidade de construir um contínuo referencial.

Em sentido lato, para Greimas, anáfora é uma relação de identidade parcial que se estabelece no discurso, no eixo sintagmático, entre dois termos, servindo para vincular dois enunciados, dois parágrafos, etc. A anáfora é chamada de gramatical, na corrente da Lingüística Textual, quando utiliza para a identificação as categorias semânticas que fazem parte do arcabouço explícito de uma língua natural, por exemplo, os pronomes. Greimas distingue anáfora gramatical de anáfora semântica. Há anáfora semântica quando um termo condensado, ou denominação, retoma uma expansão sintagmática anterior. Essa mesma relação é denominada, por Greimas, catáfora, quando o termo retomado precede, no discurso, o termo em expansão. Para esse autor, a anaforização é um dos principais procedimentos que permitem ao enunciador estabelecer e manter a isotopia discursiva, ou seja, as relações interfrasais.

À diferença das anáforas e das catáforas que, no interior dos discursos, remetem a unidades, ou a segmentos dados, os dêiticos são elementos lingüísticos que se referem à instância de enunciação. As referências dêiticas, por remeterem para fora do discurso, mais recentemente, Denis Bertrand (1985) denomina referenciação, construção de valores referenciais, atribuindo o nome referencialização às anáforas e catáforas semânticas, conjunto de processos internos ao tecido discursivo. São as estratégias de referenciação e referencialização que geram a ilusão referencial (aquilo que o texto constrói) ou o efeito de sentido de "realidade" ou de "verdade". Desta forma, o "verdadeiro" passa a ser visto como um efeito de sentido do discurso, fruto de operações de veridicção, excluindo-se, portanto, qualquer relação com o referente externo.

O sujeito da enunciação não é, pois, aquele que produz um discurso verdadeiro, mas aquele que cria um efeito de sentido 
de "verdade". A veridicção, ou o dizer verdadeiro é, então, um fazer verdadeiro por parte do sujeito da enunciação, que é responsável pela totalidade do discurso. Ao se colocar como sujeito de um discurso, nessa concepção, como afirma Greimas, o sujeito da enunciação constrói um subcódigo autônomo, ou seja, uma nova semiose na acepção hjelmsleviana. O significado não é portanto fixo, mas fruto de novas relações estabeleciadas pelo ato enunciativo. Aquilo a que se refere um texto é um semema construído que é fruto de mecanismos de referenciação e de referencialização.

As três posturas que comentamos parecem ter em comum o seguinte principio: a referência é construída no texto à medida que ele põe em funcionamento a lingua, formando um todo organizado de sentido. A forma de explicar a construção da referência é que se prende a concepções diferentes.

A Lingüistica Textual enxerga a referência a partir da linearidade da superficie textual e sua preocupação é determinar os elementos lingüísticos e cognitivos que coerentizam aquilo a que o texto se refere. Busca, por conseguinte, a nosso ver, referências fixas, mas diferentemente de Saussure, em situações ideais. A proposta Semiótica vê o texto como objeto de significação ou como construção de uma referencialização. Dessa forma, o seu objeto é a formalização dos mecanismos internos da construção do sentido, ou, pensando, a partir de Saussure e Hjelmslev, busca a explicação da construção imanente da referência. Na proposta de Pêcheux, por sua vez, que concebe o texto como objeto de ação entre dois sujeitos, a referência é fruto de fatores contextuais sócio-históricos que a determinam. A referência é, pois, a maneira de ver o mundo conforme um grupo, representando um padrão homogêneo de interpretação.

São três formas de contrato para se construir a referência, um social, fundamentado nas relaçōes pragmáticas de cenas so- 
NASCIMENTO, Edna Maria F. S. Mecanismos de referenciação e produção discursiva.

ciais, um institucional, caracterizado pelas relações de poder, e outro, discursivo, produzido no ato enunciativo.

O que podemos observar, pelos comentários que tecemos em relação à construção da referencialização é que, a partir do momento em que a Lingüística amplia o seu nivel de análise também para o texto, o contrato estabelecido na língua passa a sofrer coerções da situação onde a combinatória de signos ocorre. O significado do signo em estado de língua é modificado em uso, onde são construídas novas referências. O contrato sígnico postulado por Saussure, no começo do século, pode ser rompido. A lingua, concebida como um dicionário comum a todos usuários, passa a ser encarada como um jogo, onde interlocutores constroem sentidos. É um novo recorte, com base epistemológica diferente - a da instabilidade.

\section{Bibliografia}

AMACKER, R. (1975) Linguistique saussurienne. Genebra: Draz.

BARTHES, R. (1964) Elementos de semiologia. São Paulo: Cultrix.

BENVENISTE, E. (1976) Problemas de Lingüística Geral. São Paulo: Nacional/USP.

. (1989) Problemas de lingüística geral II. Campinas: Pontes.

BERNARDEZ, E. (1982) Introdución a la linguística del texto. Madrid: Espasa/ Calpe.

BERTRAND, D. (1985) L'espace et le sens. Germinal d' Émile de Zola. Paris: Hads-Benjamins.

DUBOIS, J. (1969) Enoncé et énonciation. Langages 13. Paris: Didier/ Larousse, p. 100-110.

DUBOIS, J. et alii (1978) Dicionário de lingüística. São Paulo: Cultrix.

GREIMAS, A. J. (1975) Sobre o sentido. Petrópolis: Vozes. . (1976) Semântica estrutural. Pesquisa de método. São Paulo: Cultrix, USP. 
Rev. ANPOLL, n. 9, p. 227-237, jul./dez. 2000

GREIMAS, A. J. e COURTÉS, J. (s.d.) Dicionário de semiótica. São Paulo: Cultrix.

HJELMSLEV, L. (1975) Prolegômenos a uma teoria da linguagem. São Paulo: Perspectiva.

KERBRAT-ORECCHIONI, C. (1980) L'énonciation de la subjectivité dans le langage. Paris: A. Colin.

LLORACH, C. (1969) A. Gramática estrutural. Ségun la escuela de Copenhague y con especial atención a la lengua espanola. Madrid: Gredos.

LOPES, E. (1993) As palavras e os dias. Ensaios sobre teoria e prática da literatura. São Paulo: EDUNESP/Editora da Universidade de Campinas.

MAINGUENEAU, D. (1989) Novas tendências em análise do discurso. São Paulo: Pontes/Editora da Universidade Estadual de Campinas. (1976) Initiation aux méthodes de l'analyse du discours. Problémes et perspectives. Paris: Hachette.

PÊCHEUX, M. (1995) Semântica e discurso. Uma afirmação do óbvio. Campinas: EDUNICAMP.

SAUSSURE, F. (1970) Curso de lingüística geral. São Paulo: Cultrix.

TODOROV, T. e DUCROT, O. (1977) Dicionário enciclopédico das ciências da linguagem. São Paulo: Perspectiva. 